\title{
O Poder do Designer: A questão da autoria sob a ótica de Adrian Forty
}

The Power of the Designer: The Authorship Issue from Adrian Forty's Perspective

MAGALHÃES, Paulo; Mestrando; Pontifícia Universidade Católica do Rio de Janeiro (PUC-Rio)

paulovsmagal@hotmail.com, Bolsista do CNPq - Brasil

CIPINIUK, Alberto; Doutor; Pontifícia Universidade Católica do Rio de Janeiro (PUC-Rio)

cipiniuk@puc-rio.br

\section{Resumo}

Sob a ótica de Adrian Forty, este artigo propõe algumas reflexões a respeito da noção de autoria no Campo do Design. A autoria é uma noção hegemônica entre os agentes de legitimação do Campo do Design e, de nossa parte, tal noção é compreendida como ultrapassada. Alinhado à Forty, nosso ponto de vista defende que o designer tem pouco - ou muito menos do que imagina - poder sobre seus projetos, e que, na grande maioria das vezes, a responsabilidade de levar seus projetos a serem manufaturados de fato está nas mãos dos empresários ou donos das indústrias. Assim, aqui buscamos elucidar, através de exemplos no Campo do Design nos dias de hoje e em tempos passados, que a questão da autoria é individualista e não contribui para o avanço científico do Campo e tampouco para a resolução dos problemas da sociedade industrial como um todo.

Palavras Chave: Campo do Design; Autoria; Adrian Forty.

\begin{abstract}
From the perspective of Adrian Forty, this article proposes some reflections about the notion of authorship in the Field of Design. Authorship is a hegemonic notion among the legitimating agents of the Design Field, and on our part, such a notion is understood as outdated. In line with Forty, our point of view is that the designer has little - or much less than he imagines - power over his designs, and that, for the most part, the responsibility for getting his designs to be actually manufactured is in the hands of entrepreneurs or owners of industries. Thus, here we seek to elucidate, through examples in the Field of Design nowadays and in past times, that the question of authorship is individualistic and does not contribute to the scientific advance of the Field nor to the resolution of the problems of industrial society as a whole.
\end{abstract}

Keywords: Design Field; Autorship; Adrian Forty. 


\section{Introdução}

No Campo do Design, tal como no Campo da Arte, quase que na totalidade das vezes, trata-se a questão da autoria de uma forma passadista. Verifica-se um aflitivo e paralisante tipo de análise em que o designer se personifica como criador único e original. Supondo agir com total autonomia e autoridade sobre seus projetos, desenvolve produtos que arrogantemente julga inovadores, isto é, pensados, projetados e realizados individualmente, sem nenhuma interferência externa, transformando tudo aquilo que existia antes em algo absolutamente novo. Até onde pode-se enxergar, essa noção parece ser hegemônica no campo, desconsiderando o modo de produção da sociedade industrial, o Capitalismo, em que todos os produtos industriais são estandardizados, além de sua principal função social ser a produção do lucro. Os designers afirmam presunçosamente que seus objetos são absolutamente funcionais ou utilitários esquecendo-se, contudo, que servem principalmente para atender aos usuários, termo que empregam para definir quem consome os objetos produzidos. Verifica-se também e, acima de tudo, que silenciam sobre o fato de que os objetos industriais são mercadorias, isto é, objetos com valor de troca e não de uso, para a produção de mais valia.

A utilidade de uma coisa, utilidade que depende das suas qualidades naturais, aparece no seu uso ou consumo, e faz dela um valor de uso. Destinado por quem os confecciona a satisfazer as necessidades ou as conveniências de outros indivíduos, um objeto é entregue pelo produtor àquela pessoa a quem é útil, a quem quer usá-lo, em troca de outro objeto, e por esse ato se converte em mercadoria. A proporção variável, em que mercadorias de espécie diferente se trocam entre si, constitui seu valor de troca. (MARX, 2016, p. 51/52)

Ademais, de modo paradoxal, é importante ressaltar, os designers insistem em dizer que sua maior preocupação é com o usuário e talvez essa afirmação seja a maior prova de que são indiferentes aos infelizes mortais que adquirem seus produtos ou mercadorias, afinal as mercadorias não são para serem usadas, como visto na referência acima, mas para serem trocadas.

Verifica-se empiricamente que existe uma especulação recorrente sobre a independência da categoria profissional dedicada à prática do design em relação ao mundo que a cerca, pois o design é considerado como se fosse uma atividade contemplativa ou espiritual. A prática do design nunca é considerada uma forma de trabalho, mas sempre um "fazer". Na maioria das vezes a noção de design se aproxima de uma ideia carismática em relação ao trabalho dos designers, isto é, não são vistos como trabalhadores, mas como "autores". Os designers seriam produtores de "obras", tal como os artistas que, a partir do nada, dão nascimento a projetos completamente inovadores, criados apenas pela inspiração de pessoas dotadas de capacidades únicas e inatas. Acontece que a realidade não é tão otimista:

Contudo, ainda que esses relatos não pretendam enganar, seu efeito é, com frequência, o de obscurecer o fato que o design envolve mais do que apenas o trabalho feito por designers e de criar a impressão falaciosa de que os designers são os únicos responsáveis pelos resultados. Embora estes preparem os designs, a responsabilidade por levá-los adiante está nas mãos do empresário; no desenvolvimento de um artigo manufaturado, é normal que se preparem muitos designs preliminares, dentre os quais o empresário escolhe um para ser produzido. (FORTY, 2007, p. 324)

Assim sendo, será realizado um estudo para compreender com maior clareza as relações entre o Campo do Design e a noção de autoria, a fim de definir como e em qual período histórico esta noção se estabelece. Para tanto será feito um levantamento bibliográfico de autores que 
escreveram sobre autoria, sendo o principal deles Adrian Forty.

\section{Revisão Bibliográfica}

Adrian Forty, em seu livro Objetos de desejo - design e sociedade desde 1750, publicado em 1986, afirma que é o empresário - dono da indústria - quem decide qual o design que encarna mais satisfatoriamente as ideias necessárias para o sucesso do produto, e que é ele quem seleciona o design do objeto a ser fabricado. Ademais, para Forty, os designers costumam falar e escrever apenas sobre o que eles mesmos fazem, colocando o design como algo que pertence totalmente ao domínio do designer. Forty afirma ainda que esse equívoco reaparece em inúmeros livros e na cobertura do design nas mídias, gerando consequências graves, como o ensino dessa noção nas escolas de design, onde os estudantes correm o risco de adquirir ilusões grandiosas acerca da natureza de seu trabalho e ficar frustrados em suas carreiras subsequentes (FORTY, 2007, p. 325).

Defendemos que essa onipotência reproduzida em larga escala, isto é, ensinada nas escolas de design é uma fantasia: o mito da autonomia criativa nos faz esquecer o problema da ideologia como determinante no design e liberta os designers da situação incômoda de que talvez não sejam mais do que meros atores no teatro da história. Trata-se de uma crença difundida de que, apesar da existência de provas em contrário, os indivíduos são os senhores de sua vontade e seu destino (FORTY, 2007, p. 326). Não é raro observar os próprios designers cheios de orgulho de sua criação, como se fossem eles os únicos responsáveis por ela, esquecendo-se que por trás da manufatura de um produto existem inúmeros fatores que não são decididos pelo designer.

Porém, para a maioria dos designers, a solução do problema não está na teoria, mas no conluio com o mito de sua própria onipotência e na total ignorância de seu papel de agentes da ideologia burguesa. Embora alguns designers reconheçam que estão envolvidos na transmissão de ideias sobre as quais não têm controle e as quais podem não compreender plenamente, é mais comum escutá-los descrever seu trabalho como se tivessem total poder sobre ele. (FORTY, 2007, p. 325)

Outro autor que estudou a noção de autoria, porém dessa vez em diversos $\operatorname{campos}^{1}$ da arte, foi Howard S. Becker em seu livro Mundos da arte. Becker ressaltava que na arte, assim como em todas as formas de trabalho, o que existiam eram práticas coletivas e não o que se divulga: trabalhos individuais realizados por pessoas especiais. Para Becker, todo o trabalho artístico envolve a atividade conjugada de um determinado número de pessoas, e estas pessoas não são apenas aquelas diretamente envolvidas com a criação da obra per se, mas também fabricantes e distribuidores tornam-se figuras importantíssimas para a realização de tais obras.

Outra atividade fundamental para a produção de obras de arte consiste no fabrico e na distribuição dos materiais e do equipamento necessários à maioria das atividades artísticas. Os instrumentos musicais, as tintas e as telas, as sapatilhas e a roupa dos bailarinos, as câmaras e as películas - todos estes elementos têm de ser fabricados e postos à disposição das pessoas que os usam para produzirem obras de arte. (BECKER, 2010, p. 29)

Becker vai além. Para ele, uma vez realizada a obra, é necessário que alguém Ihe seja

\footnotetext{
${ }^{1}$ Observe-se que o termo campo, empregado por Becker, tem uma compreensão bastante diferente de como Pierre Bourdieu o emprega. Na verdade, o termo empregado por Becker é "mundo da arte" e não campo. Campo aqui é apenas um gênero artístico ou um domínio, como o campo da música é diferente do campo da escultura, por exemplo.
} 
sensível, afetiva ou intelectualmente. Logo a obra de arte também "não ocorre sem a presença de um público que reaja e aprecie" (BECKER, 2010, p.29). O "mundo da arte" de Becker envolve uma cadeia ainda maior na sociedade:

Assim, os pintores dependem dos fabricantes de molduras, de tintas e de pinceis; dependem dos galeristas, dos colecionadores e dos conservadores dos museus para acederem aos espaços de exposição e ao apoio financeiro; dependem dos críticos e dos historiadores de arte para a justificação do seu trabalho, do Estado para as ajudas materiais, bem como das leis fiscais susceptíveis de encorajar os colecionadores a adquirirem obras e depois legá-las à sociedade. Dependem do público pelas respostas emocionais às suas obras e dos outros pintores, tanto dos seus contemporâneos como dos mais velhos, que instauram a tradição pela qual as suas obras adquirem significado. (BECKER, 2010, p.37)

Howard S. Becker ainda questiona se o artista que passa por ter realizado uma obra por si mesmo, realizou-a de fato ele próprio. Será que alguém pode modificar ou retocar uma obra original de tal modo que aquilo que nos é apresentado já não corresponde exatamente ao que o artista realmente desejava ou criou? Afirma que a reputação do criador e da obra se reforçam mutuamente. Quando a distribuição da arte implica em uma transação no mercado, o nível de reputação pode ser convertido em valor financeiro. Isso implica a decisão de retirar a autoria de uma obra a um artista famoso e admirado faz com que ela perca totalmente o seu valor de mercado. Mas é preciso lembrar que o valor de mercado não é o mesmo do que valor estético.

\section{O Design compreendido como Prática Social}

De uma posição contrária ao hegemônico, defende-se que o design deve ser entendido como prática social, isto é, um modo de trabalho como outro qualquer. Trabalho é uma forma organizada de produção, que tem a ver com uma demanda social. O trabalho de um designer não difere do trabalho de um médico, de um advogado ou de qualquer outro profissional liberal. Parece claro que todo trabalho é específico, mas os designers e suas corporações profissionais não definem isso que é específico no trabalho do design. Qual é a sua singularidade? Qual a especificidade que um designer precisa deter para ser considerado designer? Essa é a discussão pretendida nesse trabalho. Ademais, partimos do pressuposto que a prática do design, mesmo ainda não possuindo o mesmo status de uma profissão liberal, como a de médicos e advogados, tem seu lugar no mundo e eventualmente esse profissional pode ser bem remunerado, tal como advogados e médicos, ou se desejarmos, como qualquer outro trabalhador, não importando qual trabalho que ele realiza. Se uma definição clara e objetiva disso que é prática do design pode ser essencial para que o designer possa ser mais bem remunerado, não temos clareza, mas intuitivamente acreditamos que no contexto atual da sociedade industrial, essa discussão é incontornável.

Existe ainda um desnível entre a noção tradicional, a qual se distingue do que nesse artigo denominamos de "produção social". Essa noção possui viés mais politizado, no sentido de esclarecermos como se estabelecem as relações humanas dentro da sociedade industrial, marcada por uma relação de competitividade. A defesa da hegemônica noção de autoria se explica porque ela se naturalizou no Campo do Design. Em princípio estamos discutindo sobre quais critérios sob os quais se pode afirmar que uma pessoa pode ser melhor do que outra. Quem consagra a noção de que existe alguém melhor do que o outro? Por que existe a questão autoral no Campo do Design? Temos como primeiros passos a definição de uma preocupação por parte dos profissionais do Campo do Design, quando possuem consciência social, alegam que não possuem 
uma identidade profissional. Como os pares do campo hegemonicamente relutam em defini-la de modo inteligível, essa identidade foi apropriada do Campo da Arte. Assim, a fronteira do Campo do Design com o Campo da Arte parece ser, por vezes, porosa, flexível, permeável, de modo que muitas vezes não se tem a clareza se estamos falando de arte ou de design.

\section{Arte ou Design - uma permeabilidade incerta}

Em muitos exemplos, tanto nos dias de hoje como em tempos passados, mostram a figura do designer muito parecida como a de um artista: designers ganhando notoriedade nas diversas mídias assim como artistas famosos estão acostumados em receber. Parece ser que esta antiga noção, que há muito deveria ter sido desfuncionalizada, ainda permeia o Campo do Design, confundindo e amargurando muitos profissionais que buscam tal notoriedade.

Adrian Forty esclarece tal ponto logo no início de seu livro que, lembra-se, foi publicado em meados de 1986, há mais de 30 anos. Para Forty, a distinção crucial é que o que denominamos de "obras de arte" são em geral concebidas por (ou sob direção de) uma pessoa, o artista. Isso não é verdade quando se fala de bens manufaturados: a concepção e a fabricação de sua obra permitem aos artistas considerável autonomia, o que levou à crença comum de que uma das principais funções da arte é dar livre expressão à criatividade e à imaginação e, segundo o autor, tal visão certamente não é verdadeira para o design (FORTY, 2007, p. 13). Ainda assim, nota-se que a visão do designer como um "quase artista" é profundamente ensinada em nossos meios acadêmicos, seja no Brasil, seja no mundo.

É quando tentamos identificar os motivos dessas diferenças que encontramos dificuldades, que se tornam mais agudas quando levamos em conta não apenas a obra de indivíduos, mas a aparência de classes inteiras de bens que envolvem uma profusão de designers. (FORTY, 2007, p. 13)

Assim sendo, procuramos encontrar alguns exemplos vigentes tanto como hegemônicos entre os pares da profissão quanto no imaginário popular: designers que criaram fama através de seus objetos e/ou imagens, os quais muitas vezes têm pouca ou nenhuma funcionalidade. Existe também uma gama de produtos midiáticos - tais como documentários e filmes - que tratam a figura do designer como um ser humano especial, que projeta de maneira individual e autoritária os seus projetos, afinal eles são propriedade desse indescritível espírito, que não se confunde com os demais. Não revelam que por trás de tais processos existem muitos outros fatores que sem eles seria impossível que o projeto deixasse o papel.

Julga-se também importante utilizar exemplos da História do Design, a fim de esclarecer que esta visão não se trata de um aspecto de moda: ela vem permeando os tempos desde que a profissão nasceu.

\subsection{O caso de Wedgwood e o perigo da liberdade artística na fábrica}

Quando, em seu livro, Forty menciona sobre o que ele chama "os primeiros designers industriais", o autor coloca em evidência um ceramista chamado Josiah Wedgwood. Para Forty, o exemplo de Wedgwood é relevante porque, embora ele não tenha sido o primeiro proprietário de uma indústria de cerâmica, a famosa Etruria, a diferenciar as tarefas de projetar vasos e de fazêlos, Wedgwood atribuiu mais valor ao trabalho do designer do que os outros fabricantes da época (FORTY, 2007, p. 43).

A intenção de Wedgwood não era a de se tornar famoso por revolucionar a "arte" da 
cerâmica, mas sim, envolto pela ideologia comercial que se iniciava naquela época, obter recompensa monetária ou mais valor nos produtos que produzia e vendia. "A realização dessa ambição simples dependia de ser capaz de fazer mais produtos, vender mais e também, se possível, aumentar o lucro unitário" (Idem., ibidem.). Percebe-se aqui que a ambição de Wedgwood era de cunho unicamente mercadológico, não procurando manufaturar produtos que fossem objetos de luxo ou algo do gênero, mas sim encontrar soluções na área da cerâmica de modo que ele obtivesse lucro.

O caso de Wedgwood torna-se relevante uma vez que percebemos que ele teve suma importância no sentido de manter o padrão de seus produtos, e aqui percebe-se sua preocupação em não deixar que o artífice deixasse sua "marca" no produto a ser fabricado. "A intenção de Wedgwood de fazer da Queensware (um tipo de cerâmica aperfeiçoada por Wedgwood) um produto consistente e uniforme não poderia ser cumprida enquanto os trabalhadores tivessem liberdade para fazer variações idiossincráticas nos produtos" (FORTY, 2007, p. 48). Tal idiossincrasia citada não seria justamente a tal unidade, o individualismo que muitos designers tentam impor em seus projetos, chamando-os assim de obras autorais? Acredita-se que sim. Assim sendo, Wedgwood dividiu as tarefas em pelo menos sete etapas, nas quais o operário fazia geralmente uma única tarefa. Com tantos artífices encarregados pela produção de um artefato, tornou-se virtualmente impossível que estes fizessem alguma mudança drástica, de forma a descaracterizar o produto (Idem., ibidem.). Logo, Wedgwood estava, ao ir contra as prováveis "assinaturas estilísticas" (outro termo que é muito usado para denominar um design como autoral) de seus artífices dividindo as tarefas, justamente procurando ser fidedigno ao projeto inicial, sem correr riscos que estes fossem alterados. Por não deixar que seus artífices fossem "autorais", ele estava também protegendo, de certa maneira, o projeto, o design inicial, o que pode parecer um tanto quanto paradoxal para os defensores da autoria nos projetos.

Além disso, Wedgwood percebeu o valor do projetista, que à época era o modelador. Para Forty nota-se aqui um estágio de design (FORTY, 2007, p. 50). "Quando a manufatura foi dividida em processos realizados por diferentes trabalhadores, foi necessário adicionar mais um estágio, o da preparação de instruções para os vários operários: na verdade, um estágio de design" (Idem., ibidem.). Os modeladores desenvolviam os protótipos e, a partir destes, fazia-se um clichê de barro (denominado de biscoito), no qual os artesãos não apenas se baseavam, mas eram instruídos a fazerem tal qual o biscoito disponibilizado. Wedgwood tentava "fazer de seus homens, máquinas" (FORTY, 2007, p. 48), fazendo com que eles repetissem à exaustão o biscoito projetado pelo modelador para, assim, evitar que os trabalhadores introduzissem variações no trabalho. Wedgwood deu tanta importância aos modeladores que estes se tornaram os trabalhadores mais bem pagos nas cerâmicas (FORTY, 2007, p. 51). Em 1769 certos modeladores ganhavam mais do que o dobro de um artesão qualificado (Idem., ibidem.).

Apesar desses ganhos aparentemente altos, os salários dos modeladores não correspondiam necessariamente ao valor de seu trabalho. Se este excedesse aos salários pagos, a diferença seria lucro para o empresário. Uma vez que os modeladores recebiam uma taxa fixa e não royalties por seus designs, a margem do empregador também aumentava com o número de mercadorias produzidas a partir de um mesmo desenho, $\mathrm{O}$ uso de modeladores abriu, assim, caminho para maior lucratividade. (Idem., ibidem.)

Porém, Wedgwood estava descontente com o trabalho dos modeladores, pois estes mostravam dificuldades em abandonar ideias tradicionais e mudar o estilo dos artigos. Assim, Wedgwood teve uma ideia que pode, à primeira vista, ser desfavorável ao defendido no presente 
artigo. Mas perceberemos mais à frente que, pelo contrário, o modo como ele o fez apenas corrobora para o argumento do presente ensaio. A ideia de Wedgwood parece óbvia para quem queria trabalhadores que tivessem imaginação e criatividade: contratar artistas.

Tão logo Wedgwood contratou artistas, que conheciam os estilos neoclássicos que ele pretendia empregar em seus artigos, ele concluiu que eles também não correspondiam às suas expectativas por terem certos sentimentos de independência artística, o que não os tornava propensos a seguir a rigidez que Wedgwood esperava, ameaçando, assim, a disciplina e padrões que ele tentava impor (FORTY, 2007, p. 52). "As experiências de Wedgwood com artistas em sua fábrica o convenceram de que não deveria empregá-los dentro das oficinas, mas encomendar ou comprar desenhos deles" (Idem., ibidem.). Surgiam aí, talvez, os primeiros designers freelancers, e percebe-se a preocupação de Wedgwood, mais uma vez, em não permitir muita autonomia aos artistas, tudo com a finalidade de manter os padrões estabelecidos na fábrica. Aqui torna-se evidente, também, que desde o século XVIII, pelo menos, os projetos não são concebidos e materializados de acordo com a vontade de um designer, mas sim pelo empresário.

Percebe-se, através dos relatos de Adrian Forty acerca das produções de Wedgwood e como o mesmo se preocupava com a rigidez dentro da fábrica para conseguir a permanência dos padrões almejados que, desde o início da divisão do trabalho, existe a preocupação em não deixar que artesãos e artistas tenham muita autonomia sobre seus trabalhos, e que desde aquela época os desenhos encomendados possuíam rigidez, também, no briefing, visto que Wedgwood procurou artistas para fazerem projetos neoclássicos, nos quais Wedgwood percebeu que havia vantagens comerciais na utilização de artistas para desenhar suas louças (FORTY, 2007, p. 53). “À medida que estabeleciam uma identidade mais forte, as classes médias e altas procuravam se distinguir por gostos exclusivos e da moda. (...) Wedgwood foi obrigado a achar homens que tivessem contato com a alta sociedade e com o gosto dominante" (/dem., ibidem.). Talvez se esteja aqui lidando com um dos primeiros produtores a encomendar, por motivos de moda, artistas para fazer os projetos de suas encomendas, e também, assim, ajudando a formar esta noção purista e ingênua que permanece como hegemônico no Campo do Design de que designers são um pouco artistas. Mas o tratamento como ele dava aos artistas mostra, também, o quanto os produtores da época do nascimento da profissão como se conhece se preocupavam em manter padrões e não deixar que tais artistas possuíssem individualidade e liberdade criativa com os projetos encomendados pelo produtor.

\subsection{O design autoral nos dias atuais: uma breve análise}

É notório, desde o paradigma que alguns autores consideram como vigente, nesse período histórico que muitos chamam de pós-modernismo, que surgiram muitos designers que possuem a pretensão de se julgarem ou serem julgados pelo Campo do Design e/ou pelo imaginário popular como designers "autores". Mas seriam os produtos criados por eles - na grande maioria das vezes produtos de luxo - trabalhos de design de fato? Defendemos que não. Estuda-se com frequência na graduação da profissão nomes populares de indivíduos que, individual e autonomicamente, teriam mudado os padrões do design para sempre. Dificilmente encontra-se alunos formados em design que nunca tenham ouvido falar de nomes como David Carson, o "reinventor" do design editorial (que nunca se formou em uma escola de design), ou de Philippe Starck e seus diversos produtos de luxo, inclusive assinando a decoração de interiores de hotéis, como o Le Meurice em Paris, França. 
O design experimental chamava atenção para si, e o inevitável resultado era colocar seus criadores no centro das atenções. Desde os primórdios da arte comercial, sempre houve um punhado de designers que se tornaram "estrelas" da profissão, tendo suas obras aclamadas por revistas especializadas, exposições e até mesmo em monografias. (POYNOR, 2010, p.119)

Segundo Poynor (2010) foi nos anos de 1980 que o senso de auto importância no Campo do Design crescia, e crescia também sua fascinação consigo mesmo (a dos designers). "Houve um aumento significativo na quantidade de palestras informais com designers e de conferências com a participação do mesmo grupo itinerante de figurões do design internacional" (Idem., ibidem.). Nota-se aqui a insegurança por parte dos profissionais e também o surgimento de monopólios criados pelos ditos "figurões". Tais monopólios surgem em todas as esferas sociais uma vez que o modelo econômico vigente - o capitalismo - entra em colapso.

\subsubsection{Philippe Starck e o Juicy Salif: a frivolidade que enfeita}

O Juicy Salif é um espremedor de sucos que muito provavelmente quase todos designers conhecem. Fabricado desde 1990 pela marca italiana de utensílios domésticos, a Alessi, o Juicy Salif é um dos produtos mais polêmicos do design contemporâneo.

Polêmico porque coloca em xeque a questão bauhausiana de que "a forma segue a função". O espremedor, segundo muitos testes feitos por especialistas, não funciona ou funciona mal. Alguns problemas ergonômicos são verificados no produto de Philippe Starck, como o problema espacial: apenas um copo baixo cabe no vão entre os três pés do produto. E como ele não contém nenhuma espécie de filtro, as sementes caem diretamente no copo (ou até mesmo fora dele). Isso sem contar o preço: custa em torno de cinquenta euros na Europa e mais de novecentos reais no Brasil. Por esse tipo de dados não se fica convencido que Starck procurava projetar um utensílio para melhorar a relação produto/usuário, pelo contrário. Starck queria projetar um produto que, por conter sua assinatura, tivesse a "aura" de obra de arte. Isto tanto se tornou verdade que hoje em dia o espremedor integra a coleção do MoMa (Museu de Arte Moderna) em Nova lorque e muitas salas de estar como artigo de decoração de luxo.

Isso mostra que existe todo um ramo industrial voltado para algo que não é design per se, pois não se encaixa numa das principais funções do profissional: projetar objetos que possuam função, de modo a melhorar a usabilidade dos produtos já existentes. Logo julga-se aqui que o espremedor não é nem um espremedor em si, uma vez que a função dele é puramente decorativa. Temos aqui um claro exemplo de um designer que foi colocado pela sociedade como um criador ou autor que possui total autonomia criativa.

\footnotetext{
A onipotência é uma fantasia, porém atraente: o mito da autonomia criativa faz esquecer o problema da ideologia como determinante no design e liberta os designers da situação incômoda de que talvez não sejam mais do que atores no teatro da história. Surpreende mais que outras pessoas, tais como críticos e historiadores, se apeguem ao mito e isso só pode ser explicado por sua concordância com a difundida crença de que, apesar de todas provas em contrário, os indivíduos são os senhores de sua vontade e seu destino. (FORTY, 2007, p. 326)
}

Forty reflete sobre o início de tais artigos, que têm sua função descaracterizada para se tornar artigo de enfeite e/ou de luxo, terem se tornado populares. "A ênfase na pessoa do designer, com exclusão de todas as outras considerações, tem sido particularmente marcante no modo como os bens manufaturados são expostos em museus e exposições" (FORTY, 2007, p. 322). 
Parece ser claro que, desde o momento da criação do projeto do espremedor, Starck pretendia, assim como muitos de seus artigos, expor sua "obra" em exposições e museus. Pode ser que este tipo de distorção de função que um artigo de design tenha começado no início do século passado, e, segundo Forty, nota-se claramente essa ruptura na mostra "Anos Trinta", na qual objetos começaram a ser colecionáveis, ganhando, assim, o status de obra de arte. "Os produtos de designers reconhecidos e aclamados atraíam preços substancialmente mais altos do que objetos de designers anônimos" (FORTY, 2007, p. 323). Forty cita o exemplo da chaleira elétrica da AEG, com design de Peter Behrens que são compradas e vendidas por preços maiores do que as outras chaleiras da mesma época, as quais não conseguem mais do que valem como ferro velho (FORTY, 2007, p. 324).

Com o exemplo do espremedor de sucos de Philippe Starck percebe-se que existem designers que obtiveram notoriedade por criar objetos que não possuem função ou que, ainda, sua função é pervertida e o artigo se torna muito mais caro do que artigos que realmente possuem funcionalidade, e acabam se transformando em objetos de luxo, tendo serventia apenas como decoração dando, assim, um status de artista ao designer, o que vimos no subtítulo anterior como algo repudiado por produtores que se importam em manter os padrões em suas fábricas. $E$ como este mercado - o de uma casta tida como superior por produzir artefatos frívolos, porém com alta procura por suas características luxuosas - tem uma demanda grande pela procura de colecionadores de tais objetos.

\subsubsection{Abstract - a arte do design: quando a confusão aparece no título}

Foi lançado, no ano de 2017, um documentário na rede de streaming mais popular do planeta, o Netflix, uma série-documentário em que o próprio título já confunde o que é arte e o que é design. Abstract: a arte do design tem oito capítulos, sendo cada um deles focado em um designer. Os capítulos são divididos por ramos da profissão, e os profissionais são tratados como "ases" de seus respectivos ramos, tornando-os protagonistas em cada capítulo. Além disso, aparecem profissionais que não são designers por formação: observa-se um fotógrafo, um arquiteto e uma cenógrafa, o que faz por generalizar ainda mais a profissão que tenta há muito encontrar sua real identidade, sua raison d'être.

No primeiro capítulo conta-se a história de Cristoph Niemann, ilustrador de muitas capas da revista mundialmente famosa, "The New Yorker". No segundo capítulo, é contado o percurso de Tinker Hatfield, designer da indústria de calçados que dirige um departamento inteiro na gigante Nike. Neste episódio é interessante notar que o foco é no seu trabalho com a coleção air, principalmente nos vários calçados que o jogador mundialmente famoso da liga de basquete americana, Michael Jordan, usou ao longo de sua carreira. Depois, no terceiro episódio, o foco é em uma profissional que participa muito mais da indústria do show business do que da do design propriamente dito. Es Devlin é cenógrafa, e cria cenários para shows, óperas, peças de teatro e desfiles de moda. A seguir, no quarto episódio da série, apresenta-se mais um profissional que nem designer é: o arquiteto dinamarquês Bjarke Ingels. No quinto capítulo, quem protagoniza a história é o designer da indústria automobilística Ralph Gilles, responsável pelo setor da Fiat Chrysler. Depois, no sexto episódio, deparamo-nos com um nome muito famoso do design gráfico: Paula Scher, conhecida por ter projetado sistemas de identidade visual para o já citado MoMa, para o The Metropolitan Opera e, talvez o mais conhecido e reconhecido de todos os seus projetos, o logotipo e sistema de identidade visual do software Windows 8 . No sétimo e penúltimo capítulo assistimos a história de mais um profissional não designer: o fotografo Platon, outra 
figura mundialmente famosa por seus retratos que vão desde chefes de Estado Barack Obama e Vladmir Putin, passando por ícones da música pop como Tonny Bennet, Ozzy Osbourne e Bono Vox até ídolos do esporte, tais quais a musa do tênis, Serena Williams, o ídolo do futebol inglês David Beckham e o polêmico pugilista Mike Tyson. No oitavo e último capítulo conta-se a trajetória da designer de interiores Ilse Crawford, responsável por assinar vários projetos de hotéis de luxo.

Nota-se que a porosidade já pré-existente entre o Campo do Design e o Campo da Arte se torna cada vez mais porosa, uma vez que um dos maiores meios de propagação midiáticos do mundo trata a profissão com tamanha irresponsabilidade, prestando um desfavor aos estudiosos e pesquisadores que buscam justamente caracterizar que tipo de trabalho é o do designer. Adrian Forty já havia questionado este modelo no qual designers contam a história de seus designs, e acredita-se que é exatamente isto que ocorre no citado documentário.

Como os designers, em geral, falam e escrevem apenas sobre o que eles mesmos fazem, o design passou a ser visto como algo que pertence totalmente ao domínio deles. Esse equívoco reaparece em inumeráveis livros e na cobertura do design na imprensa e na televisão. $E$, com consequências mais graves, tem disso também ensinado nas escolas de design, onde os estudantes correm o risco de adquirir ilusões grandiosas sobre a natureza de seu trabalho e ficar frustrados em suas carreiras subsequentes. (FORTY, 2007, p. 325)

No exemplo do documentário percebe-se claramente que o que Forty acusava acontecer nos livros de design está se repetindo em muitas outras mídias. Forty defende que, para muitos designers, a solução de problemas não está na teoria que se aprende nas escolas e na profissão em si, mas sim no engodo com o mito da própria onipotência e na importância máxima de seu papel de agentes da ideologia burguesa. "É mais comum escutá-los (os designers) descrever seu trabalho como se tivessem total poder sobre ele." (FORTY, 2007, p. 325).

Assim sendo, verifica-se que não só os designers tidos como autorais e o público que consome tais designs legitimam tal comportamento, mas também a grande mídia. Ao publicar e vender a ideia de que tudo pode ser design, a grande mídia não colabora com a ciência, que procura cada vez mais (continuamente abafada por ideias e ideais puramente mercadológicos) compreender melhor qual é o trabalho de fato do designer na sociedade.

\section{Conclusões}

Através dos estudos dos textos de Adrian Forty e outros autores e das análises realizadas, podemos chegar a algumas conclusões. Primeiro parece claro que existe um pensamento hegemônico entre os agentes de legitimação do Campo do Design sobre autoria, justamente por esta noção existir. Se tal noção existe é pertinente concluir, logicamente, que alguém legitimou esta noção, uma vez que isto é ensinado nas escolas de design no mundo afora. Nota-se, também, que estas ideias são altamente difundidas fora do meio acadêmico, tanto no mercado quanto nas diversas mídias. Como vimos anteriormente, essas concepções são largamente divulgadas, e, se assim são, é porque alguém se beneficia com isto.

Mas quem são os tais beneficiários? É lógico concluir que são os grandes empresários, que no modelo econômico vigente, o capitalismo, fazem parte da classe de quem detém todo o poder socioeconômico. "É o empresário, e não o designer que decide qual design encarna satisfatoriamente as ideias necessárias para o sucesso do produto e que se ajusta melhor às condições materiais de produção." (FORTY, 2007, p. 325). Atualmente essas condições materiais 
servem tão somente para gerar lucro, ou mais valor.

Richard Sennett (2016) descreve muito bem o processo capitalista que envolve os bens manufaturados, utilizando-se de princípios marxistas.

Karl Marx tinha uma expressão adequada a essa psicologia do consumo, chamava de "fetichismo de mercadorias". Em O Capital ele escrevera que todo objeto manufaturado, colocado sob o capitalismo moderno, torna-se um 'hieróglifo social'; através dessa expressão ele queria dizer que as inequidades nas relações entre o patrão e o operário na produção desse objeto poderiam ser dissimuladas. A atenção era desviada das condições sociais sob as quais os objetos eram feitos para os objetos em si mesmos, caso as mercadorias adquirissem um sentido, um mistério, um conjunto de associações que não tivessem nada a ver com seu uso. (SENNETT, 2016, p.214)

Tal "mistério" descrito por Sennett, baseado em seus estudos de Karl Marx, é justamente a "aura" que tanto percebe-se e que foi analisada acima acerca de objetos frívolos, tal qual o Juicy Salif, de Philippe Starck. Fica claro que é de interesse do produtor obter lucro com tal forma de engendramento, este já inculcado no imaginário social. É exatamente isso que podemos perceber que ocorre também nos objetos de design, dado que produtos como os de Philippe Starck não teriam tanto apelo se os públicos consumidores de seus objetos não soubessem quem foi o "designer autor" que os projetou. O mesmo já foi mencionado anteriormente com objetos como a chaleira elétrica da AEG, projetada por Peter Behrens, a qual tornou-se objeto almejado por colecionadores, enquanto outras chaleiras da mesma época raramente alcancem preços maiores do que valem como ferro velho (FORTY, 2007, p. 324).

Ainda se percebe que, como dito anteriormente, a grande mídia também tem interesse em legitimar o mito do designer como autor. Para Forty, antigamente as histórias eram o meio tradicional de transmitir os mitos e que, a partir do século XX elas foram suplementadas por filmes, jornalismo, televisão e propaganda (FORTY, 2007, p.15). Assim sendo parece claro que existem motivos financeiros para que documentários como "Abstract: the art of design" procurem retratar os designers como autores que possuem talentos individuais e que o exerçam com total autonomia e autoridade.

Enfim, percebemos que pensar objetos de design desprovidos de função, ou com sua função de valor de uso pervertida em objeto frívolo ou valor de troca simbólica, apenas para gerar status, em nada contribui para a sociedade ou para o avanço da mesma. Assim sendo, se conclui que a noção de autoria no Campo do Design é um mito que apenas ajuda a corroborar na produção destes bens de manufatura citados acima, projetados e produzidos para gerar lucro de maneira sobremodo perversa e individualista. 


\section{Referências}

BECKER, Howard S. Mundos da Arte. Lisboa: Livros Horizonte, 2010.

BOURDIEU, P. A Economia das Trocas Simbólicas. 5a edição. São Paulo: Perspectiva, 2009.

FORTY, A. Objetos de desejo: design e sociedade desde 1750. São Paulo: Cosac Naify, 2007.

MARX, K. O Capital. Tradução e condensação de Gabriel Deville. 3.ed. São Paulo: Edipro, 2016.

POYNOR, R. Abaixo as regras: Design Gráfico e Pós-Modernismo. Porto Alegre: Bookman, 2010.

SENNETT, R. O declínio do homem público. Rio de Janeiro: Record, 2016. 